Doğan Tolga, Levent Fatih

Bursa Yüksek İhtisas Education and Research Hospital Cardiology Department, Bursa, Turkey

\title{
THE SHORT-TERM EFFECT OF THE COVID-19 PANDEMIC ON THE MANAGEMENT OF WARFARIN THERAPY
}

\begin{abstract}
Aim
Material and methods

The aim of this study was to investigate the short-term effect of the COVID-19 pandemic on the management of warfarin therapy used for atrial fibrillation $(\mathrm{AF})$ and prosthetic valve disease.

The study included 139 Atrial fibrillation (AF) patients and 173 prosthetic valve patients (PVP) who were using warfarin. The time in therapeutic range (TTR), International Normalized Ratio (INR) averages, the numbers of INR tests, and the non-adherence to INR monitoring (NIM) were compared for the pre-covid period (PCP) and the COVID-19 period (CP). Also, adherence to warfarin therapy was evaluated with a questionnaire.

Results

Conclusion

Keywords

For citation

Corresponding author was higher $(19.2 \%$ vs $71.5 \%, \mathrm{p}<0.001)$ in the CP. The number of INR tests was lower during the CP $(\mathrm{p}<0.001)$.The percentage of patients with $\mathrm{TTR} \geq 70 \%$ was lower during the CP $(41.7 \%$ vs $33 \%$ $\mathrm{p}=0.017$ ). Subgroup analysis showed that for PVP, TTR values and the percentage of patients with TTR $\geq 70 \%$ were similar in both the PCP and CP periods. The questionnaire showed that for $94.1 \%$ of respondents, the major cause of NIM in the CP was the COVID-19 pandemic. However, during the $\mathrm{CP}$, adherence to warfarin medication was high (95.5\%).

Lower TTR during the COVID-19 pandemic can increase bleeding and thromboembolic cases. Therefore, patients taking warfarin should be followed more closely, and more practical ways should be considered for INR testing.

INR; warfarin; TTR; COVID-19

Doğan Tolga, Levent Fatih. The short-term effect of the COVID-19 pandemic on the management of warfarin therapy. Kardiologiia. 2021;61(7):55-59. [Russian: Аоган Толга, Аевент Фатих. Краткосрочное влияние пандемии COVID-19 на ведение терапии варфарином. Кардиология. 2021;61(7):55-59]

Tolga Doğan. E-mail: drtolgad@gmail.com
\end{abstract}

\section{Introduction}

Warfarin, a vitamin $\mathrm{K}$ antagonist, is one of the most widely used drugs worldwide with indications such as atrial fibrillation $(\mathrm{AF})$, metallic heart valve and deep vein thrombosis. Warfarin in the therapeutic range significantly reduces the risk of recurrent ischemic stroke, deep vein thrombosis and pulmonary embolism [1-3]. The parameter of timein therapeutic range (TTR) is defined as the percentage of time in which the patient's International Normalized Ratio (INR) values are within the therapeutic range. A TTR value of $\geq 70 \%$ is accepted as an indicator of optimal benefit from warfarin treatment [4-6]. However, factors such as genetic, demographic and medical conditions of the patients and nonadherence to warfarin make it difficult to reach and maintain targets of $\geq 70 \%$ in TTR [7-11].

The COVID-19 virus pandemic has caused substantial increases in mortality and morbidity worldwide. As a result of the patient's anxiety about catching COVID-19, and various health policies developed to prevent the risk of transmission and spread of COVID-19, the number of outpatient clinic visits has decreased by approximately $60 \%$ [12]. It is unclear whether this reduction in outpatient visits has a negative impact on the treatment of patients.
The aim of this study was to investigate the short-term effects of the COVID-19 pandemic on patients using warfarin for $\mathrm{AF}$ or prosthetic valve disease.

\section{Material and methods}

This retrospective cohort study was conducted in Bursa Yuksek Ihtisas Training and Research Hospital in Turkey. The study protocol was approved by the Local Ethics Committee of the hospital in accordance with the Declaration of Helsinki and Good Clinical Practice Guidelines and written informed consent was obtained from all participants.

\section{Study population}

A total of 725 patients aged $\geq 18$ years who visited the cardiology outpatient clinic for INR monitoring between 10 September 2020 and 10 December 2020 were assessed for eligibility for the study. Inclusion criteria were defined as the use of warfarin for at least one year for AF or prosthetic mitral/aortic valve. Exclusion criteria were:

- (1) less than 2 INR tests in the last year;

- (2) discontinuation of warfarin due to any indication

(such as elective/emergency surgery, bleeding, stroke, switching to other anticoagulant treatments); 
- (3) hospitalization within 1 year for any reason;

- (4) using warfarin for an indication other than AF and prosthetic valve (such as deep vein thrombosis, pulmonary embolism);

- (5) visiting a different hospital at least once for the INR test;

- (6) a history of home quarantine with the diagnosis of COVID-19;

- (7) a diagnosis of both AF and a history of prosthetic valve

- (8) swiching/adding/stopping any chronic drug (s) during the previous year.

After implementation of the inclusion and exclusion criteria, 338 of 725 patients were eligible for the study. During the $\mathrm{CP}$, 5 minor bleeding events were detected, which did not require drug discontinuation or dose reduction. Informed consent for participation in the study was obtained from all the patients.

\section{Patient characteristics}

Demographic data, baseline characteristics, chronic diseases and medications which could most interact with warfarin were recorded during the outpatient clinic visits. The definition of major and non-major bleeding was made according to the International Society on Thrombosis and Haemostasis criteria [13]. The first COVID-19 case in Turkey was diagnosed on March 10, 2020, and two study periods were defined based on that date:

- Pre-Covid Period (PCP): a 6-month period from 10 September 2019 to 10 March 2020;

- Covid Period (CP): a 6-month period from 10 March 2020 to 10 September 2020.

\section{Number of INR tests, Average INR value and TTR}

The total number of INR tests, the average INR value and TTR in both periods (PCP-CP) were calculated and recorded for each patient and were then compared statistically. Time in therapeutic range (TTR) was calculated using the Rosendaal method [14]. The therapeutic INR range was accepted as $2-3$ for AF and aortic prosthetic valve, and as 2.5-3.5 for mitral prosthetic valve. The average INR value was calculated by dividing the total INR values by the number of INR tests (total of INR values in the period/total number of INR tests in the period).

\section{Non-adherence to Warfarin/INR monitoring (NIM)}

Patients with one or more intervals of $>45$ days between two consecutive INR tests were considered non-adherent to INR monitoring (NIM). A questionnaire which had been designed in a previous study, was modified to measure adherence to warfarin and to investigate the cause of NIM [15].

- (1) Question: "How often have you used warfarin

at the dose recommended by your doctor in the last month?"
- Answers: "Always (100\%)", "Almost always (90\%)", "Most of the time (75\%)", "About half of the time (50\%)" and "Less than half of the time $(<50 \%)$ ".

- (2) Question: "How often did you forget to take warfarin daily last month?"

- Answers: "Never", "Rarely", "Once a week", "2-3 times a week" and "Almost every day".

- (3) Question: "How often did you decide not to use warfarin voluntarily in the last month?"

- Answers: "Never", "Rarely", "Once a week", "2-3 times a week" and "Almost every day".

- (4) Question: "Why did you delay INR testing? (for the patients defined as NIM)"

- Answers: (a) "I felt good and did not think it was necessary".

(b) "I did not have the opportunity to go to the hospital".

(c) "I forgot that it was time for the INR test".

(d) "I did not want to come because of the COVID-19 pandemic".

Patients who answered (a) "most of the time (75\%)" or less in response to question 1, (b) "once a week" or more in response to question 2, or (c) "once a week" or more in response to question 3, were considered non-adherent to warfarin.

\section{Statistical analyses}

All statistical analyses were performed using IBM SPSS Statistics v. 21 software. Since the repeated measurements (average INR values, number of INR tests, NIM, TTR value) differed from normal distribution when examined with the Kolmogorov-Smirnov test, they were compared with the Wilcoxon signed-rank test. The dichotomous dependent variable (TR $<\% 70-T R>70$ ) was compared with the McNemar test. The patient characteristics were compared across the dichotomous dependent variable $(\mathrm{TTR}<\% 70-\mathrm{TTR}>70)$ using the Chi-square, Fisher's Exact, Mann-Whitney U or the Kruskal-Wallis tests, as appropriate. Variables with a p value of $<0.05$ in those tests were re-evaluated in univariate and logistic regression analyses to determine the independent predictors for TTR $<70 \%$.

\section{Results}

Of the 338 patients included in the study, $26(65.4 \%$ female, $61.5 \%$ AF patients) had no INR test or only one INR testduring the CP. All 26 patients stated that they did not attend hospital visits due to the COVID-19 pandemic [Questionnaire 4 (d)]. Data for those 26 patients were not included in statistical analyses because it was not possible to calculate TTR for those patients during the CP. Of the 312 patients. evaluated statistically, 139 (44.6\%) were using 
Table 1. Statistical comparison of Pre-Covid Period (PCP) and Covid Period (CP)

\begin{tabular}{|c|c|c|c|}
\hline \multirow[b]{2}{*}{ Parameters } & & \multirow[b]{2}{*}{ Covid Period } & \multirow[b]{2}{*}{$\mathbf{p}$} \\
\hline & Pre-Covid Period & & \\
\hline \multicolumn{4}{|c|}{ TOTAL $(A F+P V)$} \\
\hline Average INR levels. Median $\left(25^{\text {th }}-75^{\text {th }}\right)$ & $2,47(2,22-2,72)$ & $2,60(2,32-3,00)$ & $<0,001$ \\
\hline Number of INR tests. Median $\left(25^{\text {th }}-75^{\text {th }}\right)$ & $6,00(5,00-8,00)$ & $5,00(3,00-6,00)$ & $<0,001$ \\
\hline TTR Median $\%\left(25^{\text {th }}-75^{\text {th }}\right)$ & $66,20(49,72-84,00)$ & $54,30(29,00-80,00)$ & $<0,001$ \\
\hline Non adherent to INR monitoring $\mathrm{n}(\%)$ & $60(19,2 \%)$ & $223(71,5 \%)$ & $<0,001$ \\
\hline $\mathrm{TTR}>\% 70 \mathrm{n}(\%)$ & $130(41,7 \%)$ & $103(33 \%)$ & 0,017 \\
\hline Average INR levels. Median $\left(25^{\text {th }}-75^{\text {th }}\right)$ & $2,55(2,32-2,76)$ & $2,64(2,36-3,00)$ & $<0,001$ \\
\hline Number of INR tests. Median $\left(25^{\text {th }}-75^{\text {th }}\right)$ & $7,00(6,00-8,00)$ & $6,00(4,00-7,00)$ & $<0,001$ \\
\hline TTR Median $\%\left(25^{\text {th }}-75^{\text {th }}\right)$ & $58,80(39,25-74,60)$ & $52,50(31,35-78,00)$ & 0,122 \\
\hline Non adherent to INR monitoring $\mathrm{n}(\%)$ & $24(13,9 \%)$ & $111(64,2 \%)$ & $<0,001$ \\
\hline $\mathrm{TTR}>\% 70 \mathrm{n}(\%)$ & $51(29,5 \%)$ & $54(31,2 \%)$ & 0,804 \\
\hline TTR Median $\%\left(25^{\text {th }}-75^{\text {th }}\right)$ & $73,00(61,00-87,00)$ & $55,90(20,00-86,00)$ & $<0,001$ \\
\hline Non adherent to INR monitoring $\mathrm{n}(\%)$ & $36(25,9 \%)$ & $112(80,6 \%)$ & $<0,001$ \\
\hline $\mathrm{TTR}>\% 70 \mathrm{n}(\%)$ & $79(57,2 \%)$ & $49(35,3 \%)$ & $<0,001$ \\
\hline
\end{tabular}

warfarin because of $\mathrm{AF}$, and the remaining 173 patients (55.4\%) were prosthetic valve patients (PVP). The rates for heart failure $(25,2 \%$ vs $10,4 \%, p=0,01)$, stage 3 chronic renal disease (\%16,5 vs \%2,9, $\mathrm{p}<0,01)$, diabetes (\%18,7 vs $\% 10,4, \mathrm{p}=0,036)$, hypertension ( $\% 48,2$ vs $\% 32,9, \mathrm{p}=0,07)$ and coronary stent (\%17,3 vs $\% 3,5 \mathrm{p}<0,01)$ were higher in the AF group. The other patient characteristics were similar in both groups.

\section{Comparision of Pre-Covid Period (PCP) and Covid Period (CP)}

As a result of the statistical comparison of both periods (CP and PCP) of all patients, the average INR values were higher $(2.47$ vs $2.60 \mathrm{p}<0.001)$ and the number of INR tests was lower $(\mathrm{p}<0.001)$ in CP. The rate of NIM was significantly higher $(19.2 \%$ vs $71.5 \% \mathrm{p}<0.001)$ and there was a significant decrease in TTR values (66.2 vs $54.3 \mathrm{p}<0.001)$ in CP. The rate of patients with a TTR value of $\geq 70$ was lower during CP (41.7\% vs 33\% p=017). Subgroup analysis based on indications for warfarin showed that unlike AF patients, the decrease in TTR value in the PVP group was not significant statistically (Table 1).

\section{Factors Affecting Quality of Warfarin Treatment}

The results of the comparative analyses were as follows: (I) The number of INR tests was significantly higher in patients with $\mathrm{TTR}<70 \%$ during $\mathrm{CP}(\mathrm{p}<0.01)$ (Table2), (II) There was no statistically significant relationship between the medications and TTR during CP (Table 3), (III) Female gender and $\mathrm{CKD}$ remained independent predictors for $\mathrm{TTR}<70 \%$ when used in the univariate and multivariate logistic regression analyses. Female gender was determined to increase the probability of $\mathrm{TTR}<70 \%$ by 3.26 -fold, and CKD increased the risk 7.28-fold in CP (Table 4).

\section{Questionnaire}

The results of the questionnaire showed that only 14 of 312 patients $(4.5 \%)$ were non-adherent to warfarin medication in the last month (the first 3 questions). In question 4, 210 (94.1\%) of 223 patients who were considered NIM in CP gave the response of (d) ("I did not want to go to the hospital for INR testing because of the COVID-19 pandemic"), 9 (4\%) gave responnse (b) ("I did not have the opportunity to go to the hospital") and the remaining 4 (1.7\%) gave response (a) ("I felt good and I did not think it was necessary").

\section{Discussion}

The results of this study demonstrated that the rate of NIM and the average INR value increased significantly during $\mathrm{CP}$, whereas the TTR value, the rate of patients with TTR $\geq 70 \%$ and the number of INR tests decreased significantly. As an exception in the PVP group, the decrease in both the TTR value and the rate of patients with TTR $\geq 70 \%$ in $\mathrm{CP}$ was not significant statistically. Multivariate logistic regression found that female gender (odds ratio, 3.26 [95\% CI, 1.96-5.40]) and CKD (odds ratio, 7.28 [95\% CI,1.64-32.31]) were independent predictors of low TTR in CP. According to the results of the questionnaire, only 14 of the 312 patients (4.5\%) were found to be non-adherent to warfarin treatment in the last month. Of the 233 NIM patients, 210 (94.1\%) stated that 
Table 2. Baseline demographic and clinical characteristics of the patients and their association with TTR values in two periods

\begin{tabular}{|c|c|c|c|c|c|c|}
\hline \multirow{2}{*}{ Variables } & \multicolumn{3}{|c|}{ Pre-Covid Period (PCP) } & \multicolumn{3}{|c|}{ Covid Period (CP) } \\
\hline & $\mathrm{TTR}<\% 70$ & TTR $>\% 70$ & p & $\mathrm{TTR}<\% 70$ & TTR $>\% 70$ & $\mathbf{p}$ \\
\hline Over 65 years old, n (\%) & $74(40,7 \%)$ & $61(46,9 \%)$ & 0,271 & $88(42,1 \%)$ & $47(45,6 \%)$ & 0,554 \\
\hline Female, n (\%) & $106(58,2 \%)$ & $70(53,8 \%)$ & 0,440 & $138(66,0 \%)$ & $38(36,9 \%)$ & $<0,001$ \\
\hline No formal education, $\mathrm{n}(\%)$ & $21(11,5 \%)$ & $12(9,2 \%)$ & 0,361 & $24(11,5 \%)$ & $9(8,7 \%)$ & 0,308 \\
\hline Primary education, n (\%) & $86(47,3 \%)$ & $72(55,4 \%)$ & 0,361 & $110(52,6 \%)$ & $48(46,6 \%)$ & 0,308 \\
\hline Secondary education and more $\mathrm{n}(\%)$ & $75(41,2 \%)$ & $46(35,4 \%)$ & 0,361 & $75(35,9 \%)$ & $46(44,7 \%)$ & 0,308 \\
\hline Atrial fibrillation, $\mathrm{n}(\%)$ & $60(33 \%)$ & $79(60,8 \%)$ & $<, 001$ & $90(43,1 \%)$ & $49(47,6 \%)$ & 0,451 \\
\hline Prosthetic valve, n (\%) & $122(67 \%)$ & $51(39,2 \%)$ & $<0,001$ & $119(56,9 \%)$ & $54(52,4 \%)$ & 0,451 \\
\hline Previous ischemic stroke, $\mathrm{n}(\%)$ & $33(18,1 \%)$ & $16(12,3 \%)$ & 0,163 & $41(19,6 \%)$ & $8(7,8 \%)$ & 0,007 \\
\hline PAD, n (\%) & $6(3,3 \%)$ & $4(3,1 \%)$ & 0,913 & $6(2,9 \%)$ & $4(3,9 \%)$ & 0,633 \\
\hline Heart failure, n (\%) & $30(16,5 \%)$ & $23(17,7 \%)$ & 0,779 & $41(19,6 \%)$ & $12(11,7 \%)$ & 0,078 \\
\hline Stage 3 CKD, n (\%) & $24(13,2 \%)$ & $4(3,1 \%)$ & 0,002 & $26(12,4 \%)$ & $2(1,9 \%)$ & 0,002 \\
\hline Diabetes Mellitus, n (\%) & $18(9,9 \%)$ & $26(20 \%)$ & 0,011 & $27(12,9 \%)$ & $17(16,5 \%)$ & 0,392 \\
\hline Liver disease $\mathrm{n}(\%)$ & $4(2,2 \%)$ & $2(1,5 \%)$ & 0,676 & $6(2,9 \%)$ & $0(\% 0,0)$ & 0,083 \\
\hline Previous non-major bleeding $\mathrm{n}(\%)$ & $11(6,0 \%)$ & $2(1,5 \%)$ & 0,050 & $11(5,3 \%)$ & $2(1,9 \%)$ & 0,167 \\
\hline Previous major bleeding,n(\%) & $5(2,7 \%)$ & $0(0,0 \%)$ & 0,057 & $5(2,4 \%)$ & $0(0,0 \%)$ & 0,114 \\
\hline Hypertension, $\mathrm{n}(\%)$ & $67(36,8 \%)$ & $47(36,2 \%)$ & 0,905 & $71(34,0 \%)$ & $43(41,7 \%)$ & 0,180 \\
\hline Chronic bronchitis, $\mathrm{n}(\%)$ & $3(1,6 \%)$ & $7(5,4 \%)$ & 0,065 & $5(2,4 \%)$ & $5(4,9 \%)$ & 0,246 \\
\hline Coronary stent n (\%) & $13(7,1 \%)$ & $17(13,1 \%)$ & 0,080 & $23(11,0 \%)$ & $7(6,8 \%)$ & 0,236 \\
\hline Coronary bypass surgery, n (\%) & $14(7,7 \%)$ & $10(7,7 \%)$ & 1,000 & $16(7,7 \%)$ & $8(7,8 \%)$ & 0,972 \\
\hline Non adherent to INR monitoring n (\%) & $121(66,5 \%)$ & $102(78,5 \%)$ & 0,021 & $146(69,9 \%)$ & $77(74,8 \%)$ & 0,367 \\
\hline Number of INR tests. Median $\left(25^{\text {th }}-75^{\text {th }}\right)$ & $7,0(6,0-8,0)$ & $6,0(5,0-8,0)$ & 0,045 & $5,0(3,0-7,0)$ & $4,0(3,0-6,0)$ & $<0,01$ \\
\hline Non adherent to warfarin. Medication & - & - & - & $8(\% 3,8)$ & $6(\% 5,8)$ & 0,423 \\
\hline HAS-BLED score median (min-max) & $1(0-7)$ & $1(0-6)$ & 0,016 & $1(0-7)$ & $1(0-4)$ & 0,983 \\
\hline
\end{tabular}

Values are expressed as number $(\%)$, mean \pm standard deviation, or median [interquartile range].

PAD peripheral artery disease, CKD chronic kidney disease.

they did not want to go to the hospital for INR testing because of the COVID-19 pandemic.

Both the significant decrease in the TTR values and significant increase in INR values in CP may cause an increase in cerebral vascular events and/or bleeding complications in later periods. Therefore, options such as raising awareness about the importance of regular INR testing, applying the "drive-up anticoagulation testing service" method [16], home testing or switching to a new-generation oral anticoagulant agent may be more rational for these patients.

In a study by Apostolakis et al, female gender was shown to be an independent predictor of TTR [11]. In another study it was shown that those with normal renal function have higher TTR than patients with CKD [17]. Similarly in the current study, female gender and $\mathrm{CKD}$ were determined to be independent predictors for lower TTR. Interestingly, in patients with a TTR $<70 \%$, the numbers of INR tests were significantly higher. This may be related to warfarin dose adjustment in patients whose INR values are not within the therapeutic range because dose adjustment requires more frequent INR testing, such as once a week. In addition, no significant relationship was seen between NIM and TTR in CP $(\mathrm{p}=0.367)$. Further studies are needed to investigate which factors have a negatively effect on TTR in CP. Despite the higher rate of NIM and

Table 3. Medications of the patients and their association with TTR values in two periods

\begin{tabular}{|c|c|c|c|c|c|c|}
\hline \multirow{2}{*}{ Drugs } & \multicolumn{3}{|c|}{ Pre-Covid Period (PCP) } & \multicolumn{3}{|c|}{ Covid Period (CP) } \\
\hline & $T \Gamma R<\% 70$ & TTR $>\% 70$ & p & TTR $<\% 70$ & TTR $>\% 70$ & $\mathbf{p}$ \\
\hline ASA $100 \mathrm{mg}, \mathrm{n}(\%)$ & Covid Period (CP) & $6(4,5 \%)$ & 0,130 & $13(6,1 \%)$ & $6(5,8 \%)$ & 0,850 \\
\hline ASA $300 \mathrm{mg}, \mathrm{n}(\%)$ & 0 & 0 & - & 0 & 0 & - \\
\hline NSAIDs, n (\%) & $6(3,3 \%)$ & $1(0,8 \%)$ & 0,137 & $7(3,3 \%)$ & $0(0,0 \%)$ & 0,060 \\
\hline Loop diuretics, $\mathrm{n}(\%)$ & $35(19,2 \%)$ & $24(18,5 \%)$ & 0,864 & $43(20,6 \%)$ & $16(15,5 \%)$ & 0,285 \\
\hline Verapamil, n (\%) & $6(3,3 \%)$ & $7(5,4 \%)$ & 0,363 & $9(4,3 \%)$ & $4(3,9 \%)$ & 0,861 \\
\hline Amiodarone, $\mathrm{n}(\%)$ & $6(3,3 \%)$ & $2(1,5 \%)$ & 0,333 & $4(1,9 \%)$ & $4(3,9 \%)$ & 0,301 \\
\hline Digoxin, $\mathrm{n}(\%)$ & $16(8,8 \%)$ & $19(14,6 \%)$ & 0,108 & $23(11,0 \%)$ & $12(11,7 \%)$ & 0,865 \\
\hline $\mathrm{P}_{2} \mathrm{Y}_{12}$ inhibiters, $\mathrm{n}(\%)$ & $0(0,0 \%)$ & $3(2,3 \%)$ & 0,039 & $3(1,4 \%)$ & $0(0,0 \%)$ & 0,222 \\
\hline
\end{tabular}

NSAIDs Non-steroidal anti-inflammatory drugs, ADP Adenosine-diphosphate receptor inhibiters, ASA acetylsalicylic acid. 
Table 4. Associations of related variables with the presence of lower TTR levels

\begin{tabular}{|c|c|c|c|c|}
\hline \multirow{3}{*}{ Variables } & \multicolumn{4}{|c|}{$T \Gamma R<\% 70$} \\
\hline & \multicolumn{2}{|c|}{ Univariate } & \multicolumn{2}{|c|}{ Multivariate } \\
\hline & $\begin{array}{c}\text { OR } \\
(95 \% \mathrm{CI})\end{array}$ & $\mathbf{p}$ & $\begin{array}{c}\text { OR } \\
(95 \% \mathrm{CI})\end{array}$ & $\mathbf{p}$ \\
\hline Female & $\begin{array}{c}3,32 \\
(2,03-5,44)\end{array}$ & 0,0001 & $\begin{array}{c}3,26 \\
(1,96-5,40)\end{array}$ & 0,0001 \\
\hline $\begin{array}{l}\text { Over } \\
65 \text { years old }\end{array}$ & $\begin{array}{c}1,15 \\
(0,72-1,85)\end{array}$ & 0,55 & - & - \\
\hline $\begin{array}{l}\text { Stage } \\
\geq 3 \mathrm{CKD}\end{array}$ & $\begin{array}{c}7,17 \\
(1,67- \\
30,85)\end{array}$ & 0,008 & $\begin{array}{c}7,28 \\
(1,64- \\
32,31) \\
\end{array}$ & 0,009 \\
\hline Hypertension & $\begin{array}{c}1,39 \\
(0,86-2,26)\end{array}$ & 0,18 & - & - \\
\hline $\begin{array}{l}\text { Previous } \\
\text { Ischemic } \\
\text { Stroke }\end{array}$ & $\begin{array}{c}2,90 \\
(1,30-6,43)\end{array}$ & 0,009 & $\begin{array}{c}2,04 \\
(0,88-4,71)\end{array}$ & 0,09 \\
\hline
\end{tabular}

CKD chronic kidney disease.

decrease in INR visits, the questionnaire results showed that adherence to warfarin treatment was significantly high during the COVID-19 pandemic (95.5\%).

\section{Conclusion}

Lower TTR during the COVID-19 pandemic can increase bleeding and thromboembolic cases. Therefore patients taking warfarin can be followed up more closely and more practical ways of INR testing can be established.

\section{Limitations}

The Rosendall method can calculate TTR only between the first INR test and the last INR test of the patients. This resulted in differences between the periods in which TTR was calculated. In the questionnaire, adherence to warfarin treatment was questioned only for the previous month. Therefore, the questionnaire could be considered insufficient to evaluate non-adherence during the entire period of the COVID-19 pandemic. In addition, since the questionnaire was not applied in the pre-COVID-19 period, comparisons could not be made.

\section{No conflict of interest is reported.}

The article was received on $20 / 02 / 2021$

\section{REFERENCES}

1. Hart RG, Pearce LA, Aguilar MI. Meta-analysis: Antithrombotic Therapy to Prevent Stroke in Patients Who Have Nonvalvular Atrial Fibrillation. Annals of Internal Medicine. 2007;146(12):857-67. DOI: 10.7326/0003-4819-146-12-200706190-00007

2. Kearon C, Akl EA, Ornelas J, Blaivas A, Jimenez D, Bounameaux H et al. Antithrombotic Therapy for VTE Disease: CHEST Guideline and Expert Panel Report. Chest. 2016;149(2):315-52. DOI: 10.1016/j.chest.2015.11.026

3. Brandjes DPM, Heijboer H, Büller HR, de Rijk M, Jagt H, ten Cate JW. Acenocoumarol and Heparin Compared with Acenocoumarol Alone in the Initial Treatment of Proximal-Vein Thrombosis. New England Journal of Medicine. 1992;327(21):1485-9. DOI: 10.1056/NEJM199211193272103

4. Farsad B-F, Abbasinazari M, Dabagh A, Bakshandeh H. Evaluation of Time in Therapeutic Range (TTR) in Patients with Non-Valvular Atrial Fibrillation Receiving Treatment with Warfarin in Tehran, Iran: A Cross-Sectional Study. Journal of clinical and diagnostic research. 2016;10(9):FC04-6. DOI: 10.7860/JCDR/2016/21955.8457

5. Schmitt L, Speckman J, Ansell J. Quality Assessment of Anticoagulation Dose Management: Comparative Evaluation of Measures of Timein-Therapeutic Range. Journal of Thrombosis and Thrombolysis. 2003;15(3):213-6. DOI: 10.1023/B:THRO.0000011377.78585.63

6. Gallego P, Vilchez JA, Lane DA. Apixaban Compared With Warfarin for Stroke Prevention in Atrial Fibrillation: Implications of Time in Therapeutic Range. Circulation. 2013;127(22):2163-5. DOI: 10.1161/CIRCULATIONAHA.113.003132

7. Costa GL de B, Lamego RM, Colosimo EA, Valacio RA, Moreira M da CV. Identifying Potential Predictors of High-Quality Oral Anticoagulation Assessed by Time in Therapeutic International Normalized Ratio Range: A Prospective, Long-Term, Single-Center, Observational Study. Clinical Therapeutics. 2012;34(7):1511-20. DOI: 10.1016/j. clinthera.2012.06.002

8. Mearns ES, White C, Kohn CG, Hawthorne J, Song J-S, Meng J et al. Quality of vitamin K antagonist control and outcomes in atrial fibrillation patients: a meta-analysis and meta-regression. Thrombosis Journal. 2014;12(1):14. DOI: 10.1186/1477-9560-12-14

9. Nelson WW, Choi JC, Vanderpoel J, Damaraju CV, Wildgoose P, Fields LE et al. Impact of Co-morbidities and Patient Characteris- tics on International Normalized Ratio Control Over Time in Patients with Nonvalvular Atrial Fibrillation. The American Journal of Cardiology. 2013;112(4):509-12. DOI: 10.1016/j.amjcard.2013.04.013

10. Rose AJ, Hylek EM, Ozonoff A, Ash AS, Reisman JI, Berlowitz DR. Patient characteristics associated with oral anticoagulation control: results of the Veterans AffaiRs Study to Improve Anticoagulation (VARIA). Journal of Thrombosis and Haemostasis. 2010;8(10):2182-91. DOI: $10.1111 / j .1538-7836.2010 .03996 . x$

11. Apostolakis S, Sullivan RM, Olshansky B, Lip GYH. Factors Affecting Quality of Anticoagulation Control Among Patients With Atrial Fibrillation on Warfarin. Chest. 2013;144(5):1555-63. DOI: 10.1378/ chest.13-0054

12. Mehrotra A, Chernew M, Linetsky D, Hatch H, Cutler D. What Impact Has COVID-19 Had on Outpatient Visits? Commonwealth Fund. 2020; [Av. at: https://www.commonwealthfund.org/publications/2020/apr/impact-covid-19-outpatient-visits]. DOI: 10.26099/ DS9E-JM36

13. Schulman S, Kearon C. Definition of major bleeding in clinical investigations of antihemostatic medicinal products in non-surgical patients: Definitions of major bleeding in clinical studies. Journal of Thrombosis and Haemostasis. 2005;3(4):692-4. DOI: 10.1111/j.15387836.2005.01204.x

14. Rosendaal FR, Cannegieter SC, van der Meer FJ, Briët E. A method to determine the optimal intensity of oral anticoagulant therapy. Thrombosis and Haemostasis. 1993;69(3):236-9. PMID: 8470047

15. Reading SR, Black MH, Singer DE, Go AS, Fang MC, Udaltsova N et al. Risk factors for medication non-adherence among atrial fibrillation patients. BMC Cardiovascular Disorders. 2019;19(1):38. DOI: 10.1186/s12872-019-1019-1

16. Proietti M, Lane DA, Lip GYH. Chronic Kidney Disease, Time in Therapeutic Range and Adverse Clinical Outcomes in Anticoagulated Patients with Non-valvular Atrial Fibrillation: Observations from the SPORTIF Trials. EBioMedicine. 2016;8:309-16. DOI: 10.1016/j. ebiom.2016.04.013

17. Alhmoud E, Abdelsamad O, Soaly E, Enany RE, Elewa H. Anticoagulation clinic drive-up service during COVID-19 pandemic in Qatar. Journal of Thrombosis and Thrombolysis. 2021;51(2):297-300. DOI: 10.1007/s11239-020-02206-4 